\title{
A Physiological Signal That Prevents Motor Skill Improvements during Consolidation
}

\author{
Sanjin Tunovic, ${ }^{\star}$ Daniel Z. Press, ${ }^{\star}$ and Edwin M. Robertson \\ Center for Noninvasive Brain Stimulation, Harvard Medical School, Beth Israel Deaconess Medical Center, Boston, Massachusetts 02215
}

Different memories follow different processing pathways. For example, some motor skill memories are enhanced over wakefulness, whereas others are instead enhanced over sleep. The processing pathway that a motor skill memory follows may be determined by functional changes within motor circuits. We tested this idea using transcranial magnetic stimulation to measure corticospinal excitability at 6,21,36,96, and $126 \mathrm{~min}$ after participants learnt tasks that either were or were not enhanced over wakefulness. There was no change in corticospinal excitability after learning a motor skill that was subsequently enhanced; whereas, there was a substantial transient decrease in corticospinal excitability after learning a motor skill that was not enhanced. In subsequent experiments, we abolished the decrease in corticospinal excitability by applying theta burst stimulation to either the dorsolateral prefrontal or primary motor cortex, and induced motor skill improvements during consolidation. The motor skill improvements in each experiment were correlated with the corticospinal excitability after learning. Together, these experiments suggest that corticospinal excitability changes act as a physiological signal, which prevents improvements from developing over wakefulness, and so when this signal is abolished improvements are induced. Our observations show that the human brain can actively prevent the processing of memories, and provides insights into the mechanisms that control the fate of memories.

Key words: motor consolidation; motor skill memory; transcranial magnetic stimulation

\section{Introduction}

Different memories follow different processing pathways. Some motor skill memories are enhanced over wakefulness leading to improved performance "off-line" between training sessions. By contrast other memories have to wait for an interval of sleep before they are enhanced (Fischer et al., 2002; Walker et al., 2002; Robertson et al., 2004a; Press et al., 2005; Brown and Robertson, 2007; for review, see Robertson, 2009). One possible reason for these differences is that the enhancement of some memories may be actively prevented by functional changes within motor circuits in the human brain. To test this idea, we measured motor corticospinal excitability after tasks that do and do not show subsequent improvements over wakefulness.

Learning a sequence of movements can be achieved as participants perform what appears to them to be just a visual reaction time task. Yet, within the task the visual cue follows a repeating

Received Aug. 14, 2013; revised Feb. 14, 2014; accepted March 12, 2014.

Author contributions: S.T., D.Z.P., and E.M.R. designed research; S.T. and E.M.R. performed research; S.T. and E.M.R. analyzed data; S.T. and E.M.R. wrote the paper.

This work was supported by the National Science Foundation (Division of Behavioral and Cognitive Sciences 0921177; E.M.R.), and by the infrastructure provided by The Harvard Clinical and Translational Science Center (National Center for Research Resources and the National Center for Advancing Translational Sciences, National Institutes of Health; 8UL1TR00017-05). We thank Neechi Mosha, Umer Najib, Jocelyn Breton, and Lionel Renaud for their assistance with the conduct of the experiments described in this paper.

The authors declare no competing financial interests.

*S.T. and D.Z.P. contributed equally to this work.

Correspondence should be addressed to Dr Edwin Robertson, Berenson-Allen Center for Noninvasive Brain Stimulation, Harvard Medical School, Beth Israel Deaconess Medical Center, 330 Brookline Avenue, Kirstein Building KS-158, Boston, MA 02215. E-mail: emrobert@bidmc.harvard.edu.

DOI:10.1523/JNEUROSCI.3497-13.2014

Copyright $\odot 2014$ the authors $\quad 0270-6474 / 14 / 345302-09 \$ 15.00 / 0$ sequence. In this situation, there are substantial improvements over wakefulness (implicit task). By contrast, when skill at producing the same sequence of movements is acquired intentionally, with the participant's knowledge of the sequence, there are no performance improvements over wakefulness (explicit task; Fischer et al., 2002; Walker et al., 2002; Robertson et al., 2004a; Cohen et al., 2005; Brown and Robertson, 2007). Performance in both of these tasks is associated with activation of motor cortical networks; including the primary motor cortex (M1; Grafton et al., 1998; Aizenstein et al., 2004; for a meta-analysis, see Hardwick et al., 2013).

In our first set of experiments, we applied single pulses of transcranial magnetic stimulation (TMS) over M1 to measure corticospinal excitability and how it changed after learning tasks that do and do not show subsequent improvements (i.e., implicit vs explicit tasks). Corticospinal excitability is related to the alpha (also known as the $\mu$ ) rhythm over the motor cortex, to the amplitude of BOLD activation, and provides a measure of functional changes within motor circuits (Sauseng et al., 2009; Yuan et al., 2011). For example, corticospinal excitability rises when participants prepare or imagine performing movements (Fadiga et al., 1999; Mars et al., 2007). In subsequent experiments, using theta burst stimulation (TBS) we modified the excitability changes to test the connection between corticospinal excitability after learning and subsequent motor skill improvements that developed over wakefulness.

\section{Materials and Methods}

We performed three experiments to better understand the relationship between corticospinal excitability and subsequent motor skill improvements. 
Experiment 1. In the first experiment, we measured corticospinal excitability using transcranial magnetic stimulation (TMS; see below), which provides a baseline measure of excitability, and then participants performed and were tested ( skill $_{1}$ ) on a motor skill learning task that either does or does not show improvements over wakefulness (see Serial reaction time task). Participants then had their corticospinal excitability measured during a 4 min block; the middle of that block was 6, 21, 36, 96, and 126 min after learning (Robertson et al., 2004a; Fig. 1a). Ten hours after completing the motor learning task (10:00 A.M. to 8:00 P.M.), participants had their skill retested ( skill $\left._{2}\right)$, and completed a free recall test (for details, see Serial reaction time task). Thus, there were two groups with participants being randomly allocated to a task that either does or does not show improvements during consolidation (i.e., skill ${ }_{2}-$ skill $_{1}$ ).

Experiments 2 and 3. In the subsequent two experiments, we measured corticospinal excitability before participants performed the explicit version of the motor learning task, which does not show off-line improvements (Robertson et al., 2004a). Participants were then tested on the motor skill learning task ( skill $_{1}$ ), had TBS applied to either the right dorsolateral prefrontal cortex (DLPFC; Experiment 2) or the right M1 (Experiment 3), and had their corticospinal excitability measured during a 4 min block; the middle of that block was 6,21, 36, 96, and 126 min after learning (Figs. 2, 3). We applied either continuous TBS or intermediate stimulation. These different types of stimulation have different effects upon corticospinal excitability at least when they are applied directly to M1, and they may have the same contrasting effects upon corticospinal excitability when stimulation is applied to the DLPFC, which would allow them to be used to test the connection between corticospinal excitability and subsequent improvements (Huang et al., 2005). Ten hours after completing the motor learning task (10:00 A.M. to 8:00 P.M.), participants had their skill retested $\left(\right.$ skill $\left._{2}\right)$, and completed a free recall test (for details, see Serial reaction time task). Thus, there were two groups (continuous and intermediate), and participants were randomly allocated to each group.

Participants. Eighty right-handed (defined by the Edinburgh handedness questionnaire; Oldfield, 1971) participants were recruited. In Experiment 1, those participants assigned to the implicit task group were excluded from further analysis when their verbal report for the motor sequence exceeded three items (of a 12-item sequence) because earlier work has shown that this alone can be sufficient to interfere with motor skill processing (Robertson et al., 2004a; Press et al., 2005). The remaining 76 participants ( 37 male, $20.5 \pm 2.8$ years; mean $\pm \mathrm{SD}$ ) were distributed among the three experiments with 28 participants allocated to Experiment 1, 24 participants allocated to Experiment 2, and 24 participants allocated to Experiment 3. Participants were divided equally between the two groups in each of the experiments. During the intervals between corticospinal excitability testing (i.e., between $6,21,36,96$, and $126 \mathrm{~min}$ ) in each of the experiments participants engaged in normal daily activities, but they refrained from napping.

Serial reaction time task. We used a modified version of the serial reaction time task (SRTT; Nissen and Bullemer, 1987; Robertson, 2007). A solid circular visual cue (diameter $20 \mathrm{~mm}$, viewed from $\sim 800 \mathrm{~mm}$ ) could appear at any one of four possible positions, designated 1-4, and arranged horizontally on a computer screen. Each of the four possible positions corresponded to one of the four buttons on a response pad (RB-410, Cedrus), upon which the participant's fingers rested. When a target appeared, participants were instructed to respond by pressing the appropriate button on the pad. If the participant made an incorrect response, the stimulus remained until the correct button was selected. The position of the visual cues played out a repeating 12 -item sequence (2-3-1-4-3-2-4-1-3-4-2-1).

We used two versions of the SRTT, one showing off-line improvements and the other not showing off-line improvements over wakefulness (Robertson et al., 2004a; Cohen et al., 2005; Brown and Robertson, 2007). In the version that does not show off-line improvements, the so-called explicit task, participants were instructed that a change in the color of the stimuli from black to blue heralded the beginning of a repeating sequence (2-3-1-4-3-2-4-1-3-4-2-1). The color change was ex- clusively used to mark the introduction of the sequence, not its removal. Participants were neither told the sequence itself nor its length. By contrast, in the version that does show off-line improvements, the so-called implicit task, participants were introduced to the task as a test of reaction time, participants were not told about the sequence, and there were no cues marking the introduction of the sequence. The stimuli did not change color during this task; and instead remained black. The same regular and repeating 12 -item sequence was used in both versions of the task.

We used the same design and number of trials that in earlier work has shown substantial off-line improvements in the implicit task but minimal off-line improvements in the explicit task over wakefulness (Robertson et al., 2004a; Galea et al., 2010). There was an initial short training block of either 15 (implicit task) or 9 (explicit task) repetitions of the sequence, the main training block had either 25 (implicit task) or 15 (explicit task) repetitions, and then the test block had the same number of repetitions as the initial short training block. Participants were tested, and then $10 \mathrm{~h}$ later retested on the same task (i.e., implicit or explicit task). The retest block has the same number of repetitions as the earlier test block. The difference between skill at testing ( skill $_{1}$ ) and retesting $\left(\right.$ skill $\left._{2}\right)$ provided a measure of off-line motor skill $\left(\right.$ skill $_{2}-$ skill $\left._{1}\right)$. We used the different number of repetitions in the implicit and explicit tasks so that participants would acquire a similar amount of skill: to test for a statistically significant difference between the groups ( skill $_{1} ; 76 \pm 13 \mathrm{~ms}$ vs $57 \pm 6 \mathrm{~ms}$; mean $\pm \mathrm{SEM}$ ) would have required 57 participants to be recruited to each of the two groups (i.e., a total of 114 participants; $\alpha=$ $0.05 ; 1-\beta=0.8$; effect size $\mathrm{d}=0.53$ ).

Fifty random trials preceded and followed the sequential trials in the training and test blocks, of both the implicit and explicit tasks (Fig. 1). Within these random trials there were no item repeats (for example, -1-1- was illegal), and each item had approximately the same frequency of appearance. Each set of random trials in the training and test blocks were unique. This minimized the chance that participants might become familiar with the random trials. However, the random trials used within the implicit task were identical to those used within the explicit task, which allowed performance of motor sequence that was common to both tasks to be compared with a common set of random trials.

We administered a free recall test when participants had completed the SRTT, following retesting. For the implicit task, participants were asked if they had noticed anything about the visual cues, to describe that property, and if they had realized that there was a sequence to recall as many items of the sequence as possible. Participants accurately recalling $>3$ items from the 12-item sequence were removed from further analysis, which prevents participants from achieving declarative knowledge sufficient to prevent off-line improvements (Brown and Robertson, 2007). For the explicit task, participants had already been told about the sequence and so were simply asked to recall as many items of the sequence as possible.

TMS. Using a Magstim 200 (Magstim), we applied a single pulse of TMS over M1 and calculated the amplitude of the motor-evoked potential (MEP) to provide a measure of corticospinal excitability. We identified left M1 as the optimal location for inducing contractions in the right flexor dorsal interosseous muscle (FDI), and the lowest intensity of stimulation that was capable of inducing visible muscle contractions in at least 6 of 10 trials was defined as the motor threshold (MT; Wassermann et al., 1996). This method has been shown to consistently and accurately locate the hand area of M1 (Wassermann et al., 1996). At this site, we applied single pulses of TMS at $120 \%$ of MT, recorded the elicited MEP with surface electromyography, which provided a measure of corticospinal excitability.

Before motor skill learning, we measured baseline corticospinal excitability by applying 20 single pulses of TMS over a 4 min interval and measured the elicited MEP amplitude. We repeated this process three times with $120 \mathrm{~s}$ between each of the 4 min intervals of single pulse TMS. After the motor skill learning task, we measured corticospinal excitability by applying 20 single pulses of TMS over a 4 min interval and measured the elicited MEP amplitude. The middle of each 4 min interval of single pulse TMS was 6, 21, 36, 96, and 126 min after learning. There was a 
minimum of $10 \mathrm{~s}$ between each TMS pulse. The coil position was marked onto the scalp using permanent ink, which reduced the variability of the coil position among the baseline and subsequent time-points when elicited MEP magnitude was measured. Overall, we applied single pulse TMS over M1 to give a measure of corticospinal excitability before and after the motor skill learning tasks.

We tested the link between corticospinal excitability and subsequent off-line improvements by applying TBS to either the DLPFC (Experiment 2) or M1 (Experiment 3). We used frameless stereotaxy to identify the position of the DLPFC (Polaris, Northern Digital). T1-weighted MR images were transformed into MNI/Talairach coordinates (Brainsight, Rogue Research) and used to guide the position of the coil. The right DLPFC was defined as the coordinates $x=40, y=32, z=30$ for half the participants (i.e., for a total of 12 participants). Earlier studies have used these same coordinates to guide the stereotactic application of TMS to the DLPFC (Paus et al., 2001; Strafella et al., 2001; Sibon et al., 2007), and in turn, those studies based their coordinates upon the brain areas activated during working memory tasks (Petrides et al., 1993). These participants were then equally divided between those receiving continuous and intermediate TBS (i.e., a total of 6 participants in each group). For the other participants in Experiment 2, we positioned the coil on the lateral convexity $50 \mathrm{~mm}$ anterior to the hand area of the right M1 (identified by locating the optimal scalp position for the induction of MEPs), which is an approach used in earlier studies to locate the DLPFC (Pascual-Leone et al., 1996; Robertson et al., 2001). For participants in Experiment 3, we applied TBS at the optimal location for inducing MEPs because it provides a consistent way to identify the hand area of M1 (Wassermann et al., 1996).

Having identified the site of stimulation, we applied three TMS pulses at $50 \mathrm{~Hz}$ repeated every $200 \mathrm{~ms}$, which is the temporal pattern of TBS. We applied TBS either as an uninterrupted block of 600 pulses (i.e., $40 \mathrm{~s}$; continuous stimulation), or as a $5 \mathrm{~s}$ block of stimulation repeated every $15 \mathrm{~s}$ until all 600 pulses were delivered (i.e., $110 \mathrm{~s}$; intermediate stimulation) at an intensity of $80 \%$ of active motor threshold to the right DLPFC. Active motor threshold was found as the minimum single pulse intensity necessary to produce an MEP of $>200 \mu \mathrm{V}$ on $>5$ of 10 trials from the right FDI while the participant was maintaining a voluntary contraction of $\sim 20 \%$ of maximum (Huang et al., 2005).

In both experiments, we applied TBS using a Magpro $\times 100$ (Magventure). The commercially available butterfly coil (75 $\mathrm{mm}$ coil, Magventure) was positioned tangentially to the scalp with the coil handle oriented $135^{\circ}$ from the midsagittal axis of the participant's head with the coil pointing posteriorly (Mills et al., 1992).

Data analysis. We calculated the average MEP amplitude at baseline, and at each of the subsequent time points (i.e., 6, 21, 36, 96, and 126 min) after motor learning for each participant. The average MEP at each time point was then normalized based upon each participant's average MEP at baseline. In each experiment, we used a mixed repeated-measures ANOVA to determine the effect of group upon the changes in normalized MEP amplitude across the time points. Subsequently, we then used the ANOVA to identify changes in the normalized MEP amplitude across the time points within each group. To compare MEP amplitudes at selected time points between the groups we used unpaired $t$ tests, and to compare MEP changes within the same group we used paired $t$ tests.

Response times were defined as the time to make a correct response. Any response time longer than 2.7 SDs (i.e., the top one percentile) from a participant's mean was removed. A learning score was calculated by subtracting the average response time of the final 50 sequential trials from the average response time of the subsequent fifty random trials that immediately followed (Nissen and Bullemer, 1987; Willingham et al., 1989; Brown and Robertson, 2007). We did not use accuracy as a measure of motor skill because even with limited experience error rates are extremely low $(<2-4 \%$; Willingham et al., 1989; Robertson et al., 2004a; Cohen et al., 2005). We calculated skill before the interval ( skill $_{1}$ ) using the test block of the first session, and after the $10 \mathrm{~h}$ interval using the retest block (skill ${ }_{2}$; Fig. 2). The difference between skill at testing and resting provide a measure of off-line improvements occurring during consolidation ( skill $_{2}-$ skill $_{1}$; Walker et al., 2002; Robertson et al., 2004a,b;
Walker and Stickgold, 2004; Galea et al., 2010). We used a mixed repeated-measures ANOVA to compare changes in motor skill between testing and retesting across the groups, and a paired $t$ test was used to compare motor skill at testing and retesting within each group. All the $t$ tests used in the analysis of this study were two-tailed.

\section{Results}

\section{Experiment 1}

We found that the implicit and explicit tasks had significantly different effects upon the subsequent corticospinal excitability (mixed repeated-measures ANOVA, $F_{(5,130)}=3.16, p=0.01$; Fig. 1 ), and consistent with earlier work the tasks showed significantly different off-line improvements $\left(\right.$ skill $_{2}-$ skill $_{1}$; mixed repeatedmeasures ANOVA, $F_{(1,26)}=11.8, p=0.002$; Robertson et al., 2004a; Spencer et al., 2006). Yet, there was no significant difference in the off-line change between testing and retesting in participants' performance during the random trials $\left(F_{(1,26)}=0.629\right.$, $p=0.435)$. There was also no significant difference in initial skill between the groups $\left(\right.$ skill $_{1} ; 76 \pm 13 \mathrm{~ms}$ vs $57 \pm 6 \mathrm{~ms}$; mean \pm SEM; unpaired $t$ test, $\left.t_{(26)}=1.31, p=0.2\right)$, and there was also no significant difference between the groups in the baseline corticospinal excitability (MEP amplitudes; $1.12 \pm 0.24 \mathrm{mV}$ vs $1.4 \pm$ $0.17 \mathrm{mV}$; mean \pm SEM; unpaired $t$ test, $\left.t_{(26)}=1.13, p=0.266\right)$.

After the implicit motor learning task there were no significant changes in corticospinal excitability from baseline (repeated-measures ANOVA, $F_{(5,65)}=0.95, p=0.451$ ), and there were significant off-line improvements in task performance $\left(57 \pm 6 \mathrm{~ms}\right.$ vs $91 \pm 7 \mathrm{~ms}$; mean $\pm \mathrm{SEM}$; paired $t$ test, $t_{(13)}=4.103$, $p=0.001)$. By contrast, following the explicit motor learning task there was a significant change in corticospinal excitability from baseline (repeated-measures ANOVA, $F_{(5,65)}=5.1, p<0.001$ ), and no significant off-line improvements in task performance $\left(76 \pm 13 \mathrm{~ms}\right.$ vs $60 \pm 11 \mathrm{~ms}$; mean $\pm \mathrm{SEM}$; paired $t$ test, $t_{(13)}=$ $1.33, p=0.206)$. After learning the explicit task there was a significant decrease in corticospinal excitability from baseline at the 6 min time point $\left(-28 \pm 5 \%\right.$; mean \pm SEM; paired $t$ test, $t_{(13)}=$ 5.096, $p<0.001$ ), which was a significantly greater change than that observed after the implicit task $(-28 \pm 6 \%$ vs $7 \pm 5 \%$; mean \pm SEM; unpaired $t$ test, $t_{(26)}=4.64, p<0.001$; Fig. 1$)$. However, corticospinal excitability following the implicit and explicit tasks did not differ significantly at any of the subsequent time points following learning (all unpaired $t$ tests, $t_{(26)}<1, p>$ 0.45; Fig. 1). Participants in the explicit task group were told that they were learning a sequence of finger movements; whereas, those in the implicit task group were introduced to the task as a test of reaction time, and so there was a significant difference between participants' recall of the sequence $(5 \pm 1$ vs $0.5 \pm 0.2$; mean \pm SEM; unpaired $t$ test, $\left.t_{(26)}=4.25, p<0.001\right)$. Overall, the two tasks showed different off-line improvements in performance, and the corticospinal excitability changes after these tasks differed at only one time point. Using the single time point at which corticospinal excitability did differ between the tasks, we found a significant correlation between the corticospinal excitability and the subsequent off-line improvements in the implicit task $\left(r=0.55, F_{(1,12)}=5.2, p=0.041\right)$ but not in the explicit task $\left(r=0.359, F_{(1,12)}=1.7, p=0.21\right.$; Fig. 1$)$.

\section{Experiment 2}

Using TBS to modify corticospinal excitability; we sought to test the connection between excitability and off-line improvements. We applied TBS to the DLPFC because it is activated during motor sequence learning tasks, like those used in the current study, it is functionally connected to M1, and applying stimulation to this brain area has been shown to affect corticospinal 


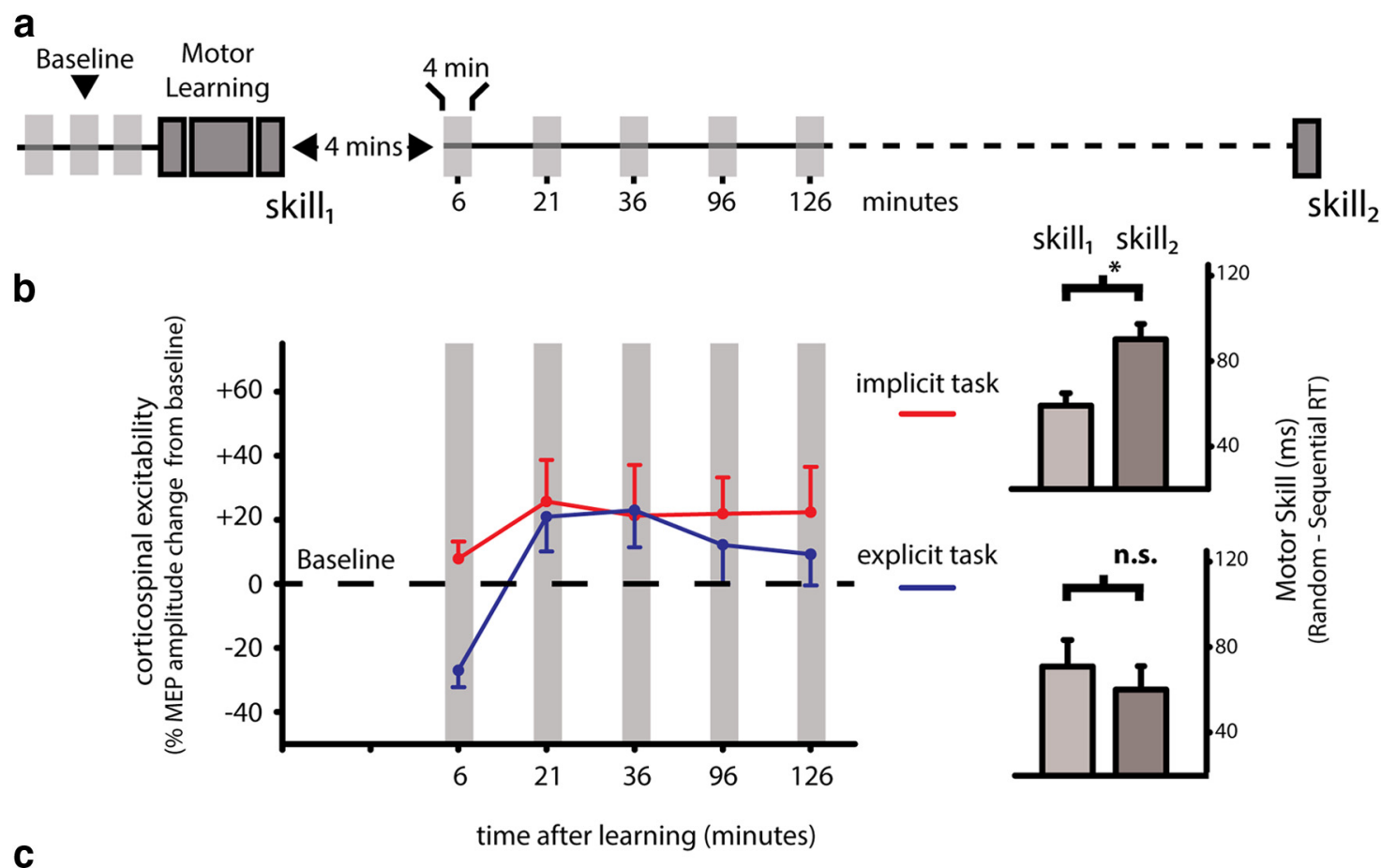

C

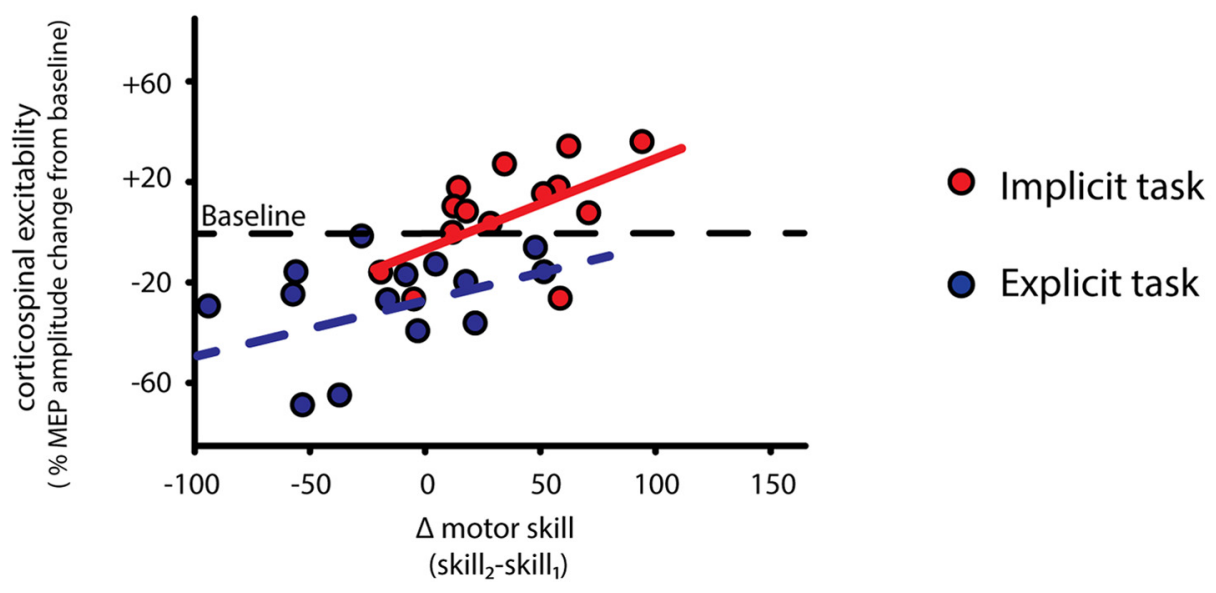

Figure 1. Experiment 1, changes in corticospinal excitability after motor learning. $\boldsymbol{a}$, We measured participants' baseline corticospinal excitability as the magnitude of the MEPs in the right hand elicited by single pulses of TMS applied to the left motor cortex. Participants then learnt either the implicit or explicit task using their right-hand, had their skill tested (skill; ;ight gray bar; mean \pm SEM), and then had their MEP amplitude measured during a 4 min block; the middle of that block was 6, 21,36, 96, and 126 min after learning (blue or red circle; normalized MEP amplitude; mean \pm SEM). Participants were then retested on the task $10 \mathrm{~h}$ after initial testing (skill ${ }_{2}$; dark gray bar; mean $\pm \mathrm{SEM}$ ). We normalized the MEP at each time point against the baseline measured before learning, and motor skill was calculated as the difference in response time (RT) during the sequential and random trials. $\boldsymbol{b}$, We found a significant decrease in corticospinal excitability from baseline following the explicit task (repeated-measures ANOVA, $F_{(5,65)}=5.1, p<0.001$ ), and no significant off-line motor skill improvements (paired $t$ test, $t_{(13)}=1.33, p=0.206 ;$ n.s.). By contrast, there was no significant decrease in corticospinal excitability from baseline following the implicit task (repeated-measures ANOVA, $F_{(5,65)}=0.95, p=0.451$ ), and significant off-line motor skill improvements (paired $t$ test, $t_{(13)}=4.103, p=0.001 ;{ }^{*}$ ). $c$, Using the single time point at which corticospinal excitability did differ between the tasks, we found a significant correlation between the corticospinal excitability and off-line improvements in the implicit task $\left(r=0.55, F_{(1,12)}=5.2, p=0.041\right)$ but not in the explicit task $\left(r=0.359, F_{(1,12)}=1.7, p=0.21\right)$.

excitability (Civardi et al., 2001; Willingham et al., 2002; Schendan et al., 2003; Hasan et al., 2013). Intermediate and continuous TBS to M1 can have contrasting effects upon corticospinal excitability (Huang et al., 2005). They may similarly have contrasting effects upon corticospinal excitability when applied to the DLPFC, which would allow them to be used to test the connection between corticospinal excitability and subsequent off-line improvements. To prevent stimulation from affecting learning and so indirectly affecting off-line improvements we applied stimulation after learning (Robertson et al., 2001; Hauptmann et al., 2005).

We found that intermediate and continuous TBS when applied after the explicit task had significantly different effects upon the subsequent pattern of corticospinal excitability (mixed repeated-measures ANOVA, $F_{(5,110)}=4.1, p=0.002$; Fig. 2 ), and upon off-line improvements ( skill $_{2}-$ skill $_{1}$; mixed repeatedmeasures ANOVA, $\left.F_{(1,22)}=6.24, p=0.02\right)$. Yet, there was no significant difference in the off-line change between testing and retesting in participants' performance during the random trials $\left(F_{(1,22)}=1.04, p=0.320\right)$. There was also no significant difference in initial skill between the groups ( skill $_{1} ; 71 \pm 17 \mathrm{~ms}$ vs $66 \pm$ $9 \mathrm{~ms}$; mean $\pm \mathrm{SEM}$; unpaired $t$ test, $t_{(22)}=0.268, p=0.791$ ), and there was no significant difference between the groups in the baseline corticospinal excitability (MEP amplitudes; $1.01 \pm 0.2$ $\mathrm{mV}$ vs $1.16 \pm 0.16 \mathrm{mV}$; mean $\pm \mathrm{SEM}$; unpaired $t$ test, $t_{(22)}=0.58$, $p=0.568)$. 
a

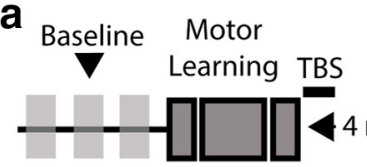

skill $_{1}$
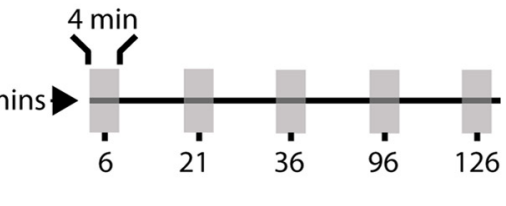

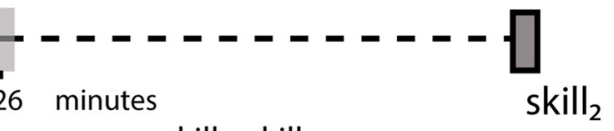

b
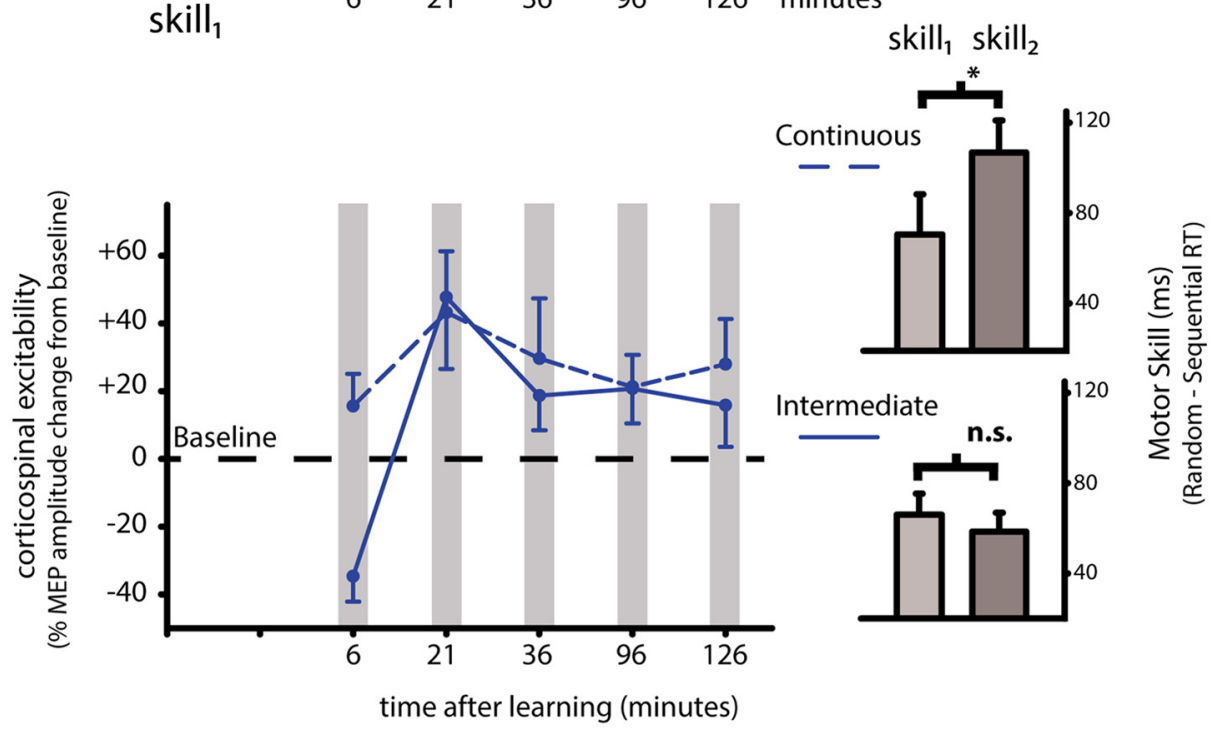

C

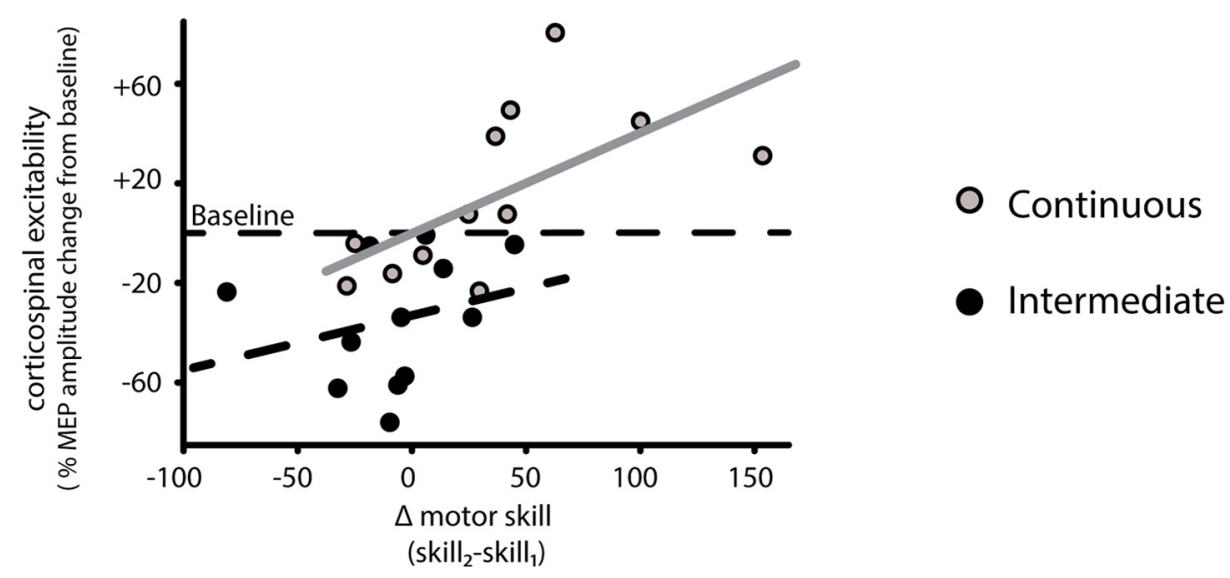

Figure 2. Experiment 2, modifying corticospinal excitability by applying stimulation to the DLPFC after motor learning, and the consequences for off-line motor skill improvements. $\boldsymbol{a}$, We measured participants' baseline corticospinal excitability as the magnitude of the MEPs in the right hand elicited by single pulses of TMS applied to the left motor cortex. Participants then learnt the explicit task using their right-hand, and had their skill tested (skill; ; light gray bar; mean \pm SEM). After learning, we applied TBS (either continuous or intermediate). Participants then had their MEP amplitude measured during a 4 min block; the middle of that block was 6, 21,36, 96, and 126 min after learning (blue circle; normalized MEP amplitude; mean \pm SEM). Participants were then retested on the task $10 \mathrm{~h}$ after initial testing ( $\left(\mathrm{kill}_{2}\right.$; dark gray bar; mean \pm SEM). We normalized the MEP at each time point against the baseline measured before learning, and motor skill was calculated as the difference in RT during the sequential and random trials. $\boldsymbol{b}$, There remained a significant decrease in corticospinal excitability after the explicit task and intermediate stimulation (paired $t$ test, $t_{(11)}=4.689, p=0.001$ ), and there were no significant off-line improvements (paired $t$ test, $t_{(11)}=0.835, p=0.421$; n.s.). By contrast, there was no longer a significant decrease in corticospinal excitability after the explicit task and continuous stimulation (paired $t$ test, $t_{(11)}=1.63, p=0.131$ ), and there were significant off-line improvements (paired $t$ test, $t_{(11)}=2.4, p=$ $\left.0.034 ;{ }^{*}\right)$. c, Using the single time point at which corticospinal excitability did differ between the continuous and intermediate groups, we found a significant correlation between the corticospinal excitability and off-line improvements in the continuous group $\left(r=0.623, F_{(1,10)}=6.33, p=0.031\right)$ but not in the intermediate group $\left(r=0.244, F_{(1,10)}=0.635, p=0.444\right)$.

After the explicit task and subsequent intermediate TBS there were significant corticospinal excitability changes (repeatedmeasures ANOVA, $\left.F_{(5,55)}=5.49, p<0.001\right)$ with a substantial decrease in corticospinal excitability occurring at the 6 min time point $\left(-35 \pm 7 \%\right.$; mean \pm SEM; paired $t$ test, $t_{(11)}=4.689, p=$ 0.001 ), and no significant off-line improvements ( skill $_{1}, 66 \pm 9$ vs skill $_{2}, 58 \pm 8 \mathrm{~ms}$; mean $\pm \mathrm{SEM}$; paired $t$ test, $t_{(11)}=0.835, p=$ $0.421)$. So, in the intermediate group there was still a decline in excitability after learning, and there were still no off-line improvements. By contrast, after the explicit task and subsequent continuous TBS there was no significant corticospinal excitabil- ity changes (repeated-measures ANOVA, $F_{(5,55)}=1.36, p=$ 0.2554 ) with no significant decrease in corticospinal excitability from baseline at the $6 \mathrm{~min}$ time point after learning $(+15 \pm 9 \%$, mean \pm SEM; paired $t$ test, $\left.t_{(11)}=1.63, p=0.131\right)$, and significant off-line improvements ( skill $_{1}, 71 \pm 17$ vs skill $_{2}, 107 \pm 14 \mathrm{~ms}$; mean \pm SEM; paired $t$ test, $\left.t_{(11)}=2.4, p=0.034\right)$. The pattern of corticospinal excitability changes and off-line improvements did not differ significantly between those that had and had not benefited from stereotactic localization of the DLPFC in either the intermediate (excitability; mixed repeated-measures ANOVA, $F_{(5,50)}=0.630, p=0.678$; skill $_{2}-$ skill $_{1}$; mixed repeated- 
measures ANOVA, $\left.F_{(1,10)}=0.672, p=0.45\right)$ or continuous groups (excitability; mixed repeated-measures ANOVA, $F_{(5,50)}=$ 0.427, $p=0.827$; skill ${ }_{2}-$ skill $_{1}$; mixed repeated-measures ANOVA, $\left.F_{(1,10)}=3.0, p=0.12\right)$.

At the 6 min time point, corticospinal excitability was significantly greater following continuous than following intermediate TBS $\left(115 \pm 9 \%\right.$ vs $65 \pm 7 \%$; mean \pm SEM; unpaired $t$ test, $t_{(22)}=$ $4.16, p<0.001)$. But at all other time points there was no significant difference in corticospinal excitability between the groups (i.e., intermediate vs continuous; all unpaired $t$ tests, $t_{(22)}<1, p>$ $0.5)$. There was also no significant difference between the groups in participants' recall for the sequence $(6.5 \pm 1$ vs $4.9 \pm 0.8$; mean \pm SEM; unpaired $t$ test, $\left.t_{(22)}=1.3, p=0.202\right)$. Overall, the two groups showed different off-line improvements, and the corticospinal excitability changes differed at only one time point. Using the single time point at which corticospinal excitability did differ between the complete groups, we found a significant correlation between the corticospinal excitability and the subsequent off-line improvements in the continuous group $(r=0.623$, $\left.F_{(1,10)}=6.33, p=0.031\right)$, but not in the intermediate group $(r=$ $0.244, F_{(1,10)}=0.635, p=0.444$; Fig. 2).

\section{Experiment 3}

We sought to provide a further test of the connection between corticospinal excitability and off-line improvements, this time by applying TBS to the right M1. Intermediate and continuous TBS to M1 can have contrasting effects upon corticospinal excitability, which allows them to be used to test the connection between corticospinal excitability and subsequent off-line improvements (Huang et al., 2005). We again applied stimulation after learning, to prevent stimulation from affecting learning and so indirectly affecting off-line improvements (Robertson et al., 2001; Hauptmann et al., 2005).

We found that intermediate and continuous TBS when applied after the explicit task had significantly different effects upon the subsequent pattern of corticospinal excitability (mixed repeated-measures ANOVA, $F_{(5,110)}=4.1, p=0.002$; Fig. 3 ), and upon off-line improvements (skill $2-$ skill $_{1}$; mixed repeatedmeasures ANOVA, $\left.F_{(1,22)}=6.43, p=0.02\right)$. Yet, there was no significant difference in the off-line change between testing and retesting in participants' performance during the random trials $\left(F_{(1,22)}=0.705, p=0.410\right)$. There was also no significant difference in initial skill between the groups ( skill $_{1} ; 68 \pm 11 \mathrm{~ms}$ vs $61 \pm$ $23 \mathrm{~ms}$; mean \pm SEM; unpaired $t$ test, $t_{(22)}=0.319, p=0.753$ ), and there was no significant difference between the groups in the baseline corticospinal excitability (MEP amplitudes; $1.8 \pm 0.2$ $\mathrm{mV}$ vs $1.5 \pm 0.2 \mathrm{mV}$; mean $\pm \mathrm{SEM}$; unpaired $t$ test, $t_{(22)}=1.054$, $p=0.303)$.

After the explicit task and subsequent intermediate TBS there were significant corticospinal excitability changes (repeatedmeasures ANOVA, $\left.F_{(5,55)}=6.901, p<0.001\right)$ with a substantial decrease in corticospinal excitability occurring at the 6 min time point $\left(-25 \pm 4 \%\right.$; mean \pm SEM; paired $t$ test, $t_{(11)}=6.57, p<$ 0.001 ), and no significant off-line improvements (skill, $68 \pm 11$ vs skill $2,63 \pm 15 \mathrm{~ms}$; mean $\pm \mathrm{SEM}$; paired $t$ test, $t_{(11)}=0.7, p=$ $0.499)$. So, in the intermediate group there was still a decline in excitability after learning, and there were still no off-line improvements. By contrast, after the explicit task and subsequent continuous TBS there was no significant corticospinal excitability changes (repeated-measures ANOVA, $F_{(5,55)}=1.8, p=0.13$ ) with no significant decrease in corticospinal excitability from baseline at the 6 min time point after learning $(+9 \pm 5 \%$, paired $t$ test, $t_{(11)}=1.8, p=0.1$ ), and significant off-line improvements
( skill $_{1}, 60 \pm 23$ vs skill $2,82 \pm 20 \mathrm{~ms}$; mean \pm SEM; paired $t$ test, $\left.t_{(11)}=2.69, p=0.021\right)$. At the 6 min time point, corticospinal excitability was significantly greater following continuous than following intermediate TBS $(109 \pm 5 \%$ vs $75 \pm 4 \%$; mean \pm SEM; unpaired $t$ test, $\left.t_{(22)}=5.42, p<0.001\right)$. But at all other time points there was no significant difference in corticospinal excitability between the groups (i.e., intermediate vs continuous; all unpaired $t$ tests, $\left.t_{(22)}<1.5, p>0.1\right)$. There was also no significant difference between the groups in participants' recall for the sequence $\left(6.5 \pm 1\right.$ vs $5.2 \pm 1$; mean \pm SEM; unpaired $t$ test, $t_{(22)}=$ $0.8, p=0.426)$. Overall, the two groups showed different off-line improvements, and the corticospinal excitability changes differed at only one time point. Using the single time point at which corticospinal excitability did differ between the groups, we found a significant correlation between the corticospinal excitability and the subsequent off-line improvements in the continuous group $\left(r=0.819, F_{(1,10)}=20.4, p=0.001\right)$, but not in the intermediate group $\left(r=0.188, F_{(1,10)}=0.365, p=0.559\right.$; Fig. 3$)$. In sum, we found that regardless of how the decrease in corticospinal excitability after learning was prevented, whether by applying continuous stimulation to the right DLPFC (Experiment 2) or the right M1 (Experiment 3) it was possible to induce subsequent off-line improvements. Together these experiments demonstrate the critical importance of corticospinal excitability, as opposed to a mechanism linked to a specific anatomical pathway, in determining the fate of a motor skill memory (not-enhanced vs enhanced).

\section{Discussion}

Our observations from across the three experiments converge to demonstrate a connection between corticospinal excitability and off-line improvements. We found that: (1) a decrease in corticospinal excitability leads to no off-line improvements, whereas, no change in corticospinal excitability leads to off-line improvements; (2) preventing the decrease in corticospinal excitability, by applying continuous TBS to either DLPFC or M1, induced off-line improvements; and (3) across the experiments there was a correlation between corticospinal excitability after learning and the subsequent off-line improvements, which was maintained even when corticospinal excitability was modified. Together, these experiments suggest that corticospinal excitability changes are tightly linked with those physiological events that are responsible for controlling off-line improvements.

Following the implicit motor sequence task there was no change in corticospinal excitability and there were subsequently off-line improvements; whereas, following the explicit motor sequence task there was a decrease in corticospinal excitability and subsequently no off-line improvements. The different corticospinal excitability changes after learning may be exclusively related to the different properties of the learning tasks. For example, participants' declarative knowledge for the sequence differed in the implicit and explicit tasks, and this may be responsible for the different corticospinal excitability changes. Alternatively, corticospinal excitability changes may not only be the result of past learning; they may also be linked to the future development of off-line improvements. Consistent with this latter perspective, we found a positive correlation between corticospinal excitability after learning in the implicit task and the subsequent off-line motor skill improvements (Fig. 1). By modifying corticospinal excitability with TBS, we sought to further test the relationship between corticospinal excitability and the subsequent off-line improvements. 


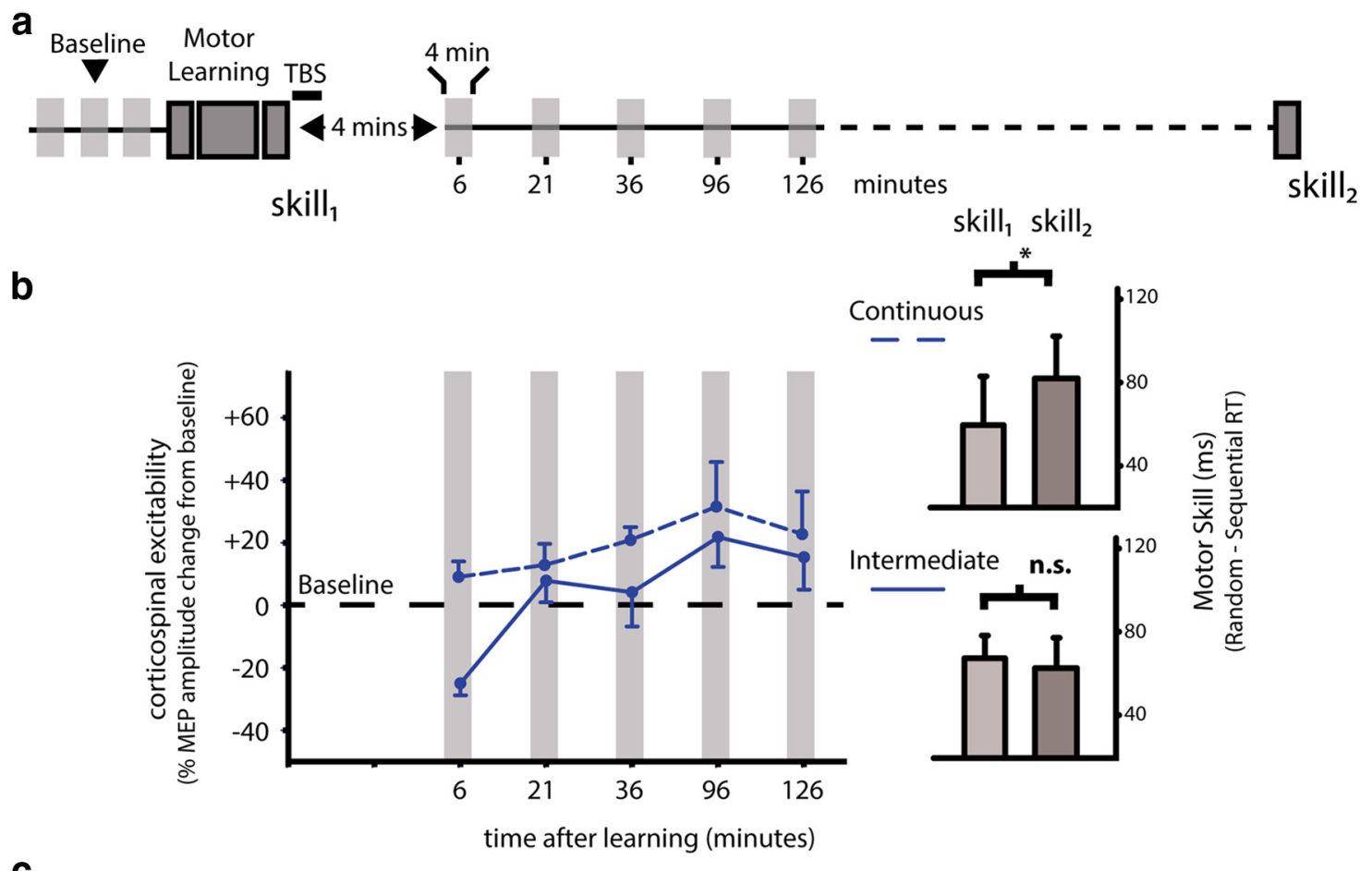

C

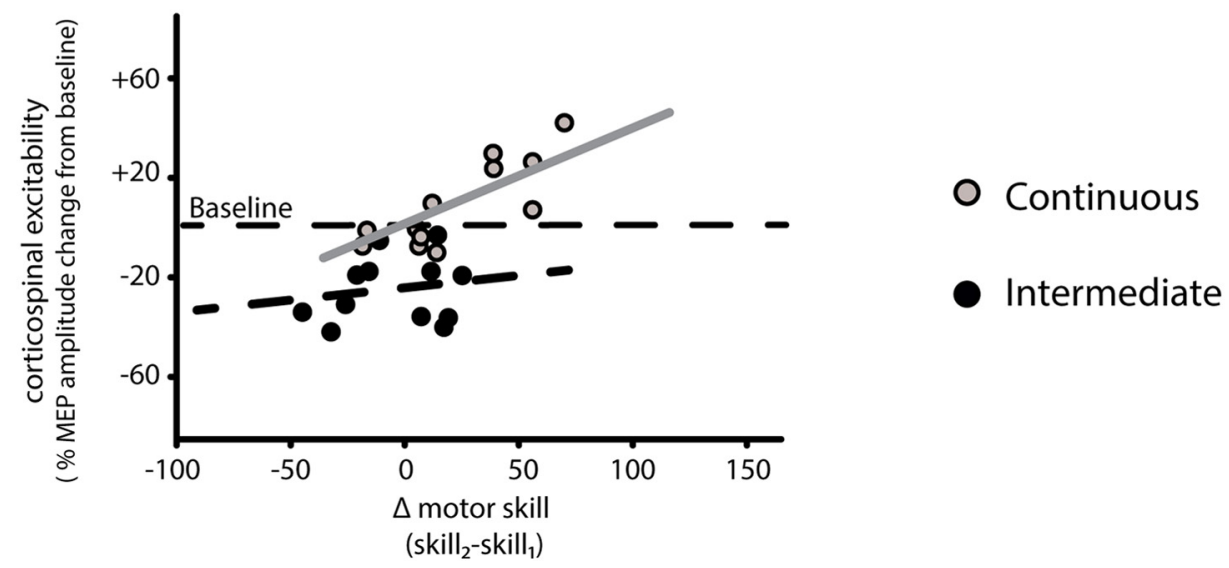

Figure 3. Experiment 3, modifying corticospinal excitability by applying stimulation to the M1 after motor learning, and the consequences for off-line motor skill improvements. $\boldsymbol{a}$, As in Experiment 2, we measured participants' baseline corticospinal excitability, then participants learnt the explicit task using their right-hand, and had their skill tested (skill; ; light gray bar; mean \pm SEM). After learning, we applied TBS (either continuous or intermediate), measured participants' MEP amplitude during a 4 min block; the middle of that block was 6, 21, 36, 96, and 126 min after learning (blue circle; normalized MEP amplitude; mean \pm SEM). Participants were then retested on the task $10 \mathrm{~h}$ after initial testing (skill ${ }_{2}$; dark gray bar; mean \pm SEM). We normalized the MEP at each time point against the baseline measured before learning, and motor skill was calculated as the difference in RT during the sequential and random trials. $\boldsymbol{b}$, There remained a significant decrease in corticospinal excitability after the explicit task and intermediate stimulation (paired $t$ test, $t_{(11)}=6.57, p<0.001$ ), and there were no significant off-line improvements (paired $t$ test, $t_{(11)}=0.7, p=0.499 ;$ n.s.). By contrast, there was no longer a significant decrease in corticospinal excitability after the explicit task and continuous stimulation (paired $t$ test $\left., t_{(11)}=1.8, p=0.1\right)$, and there were significant off-line improvements (paired $t$ test, $t_{(11)}=2.69, p=0.021 ;{ }^{*}$ ). $c$, Using the single time point at which corticospinal excitability did differ between the continuous and intermediate groups, we found a significant correlation between the corticospinal excitability and off-line improvements in the continuous group $\left(r=0.819, F_{(1,10)}=20.4, p=0.001\right)$ but not in the intermediate group $\left(r=0.188, F_{(1,10)}=0.365, p=0.559\right)$.

We applied stimulation to either the DLPFC or M1 and found a consistent relationship between corticospinal excitability and off-line improvements. When we applied intermediate stimulation after the explicit task there continued to be a decrease in corticospinal excitability and no off-line improvements. By contrast, when we applied continuous stimulation after the explicit task there was no decrease in corticospinal excitability, and substantial off-line improvement were induced (Figs. 2, 3). Thus, modifying corticospinal excitability modified the off-line improvements, which suggests a connec- tion between corticospinal excitability and the subsequent development of off-line improvements.

However, the connection between off-line improvements and corticospinal excitability changes could simply be that they are both independent effects of stimulation. The improvements may have simply been caused by stimulation disrupting participants' declarative knowledge for the sequence, and the change in corticospinal excitability may be an unrelated physiological consequence of stimulation. Disrupting declarative knowledge can induce off-line improvements (Brown and Robertson, 2007; 
Robertson, 2009). However, we could find no significant difference in participants' declarative recall following continuous stimulation, which induced off-line improvements, and intermediate stimulation, which did not induce off-line improvements at either site of stimulation. So, the off-line improvements induced by stimulation over DLPFC or M1 did not depend upon a disruption of declarative knowledge.

Instead of being independent, corticospinal excitability was linked to the off-line improvements induced by continuous stimulation. We found a correlation between corticospinal excitability and the induced off-line improvements following continuous stimulation to DLPFC or M1 (Figs. 2, 3). Applying stimulation to DLPFC or M1 affected different anatomical pathways; nonetheless, applying stimulation to either site modified corticospinal excitability and modified the subsequent development of off-line improvements. Thus, induced improvements are not due to modifying the function of a particular anatomical pathway; instead, they are due to changes in corticospinal excitability. Overall, our experiments provide converging evidence for a connection between corticospinal excitability and off-line improvements, and that modification to corticospinal excitability either by applying stimulation to the DLPFC or M1 alter the fate of a memory determining those that will or will not be enhanced over wakefulness.

We applied stimulation to the DLPFC or M1 because several studies have shown that this can alter corticospinal excitability, which provided us with a means to test the connection between corticospinal excitability and off-line improvements (Civardi et al., 2001; Huang et al., 2005; Hasan et al., 2013). In both experiments, continuous stimulation was used to prevent a decrease in corticospinal excitability (Figs. $2 B, 3 B$ ). However, generally when continuous stimulation is applied it leads to a decrease in corticospinal excitability (Huang et al., 2005). Yet, these effects upon corticospinal excitability occur when stimulation is applied without any associated behavioral task, whereas in the current study, stimulation was applied after a motor learning task. Performing a motor learning task can alter the subsequent effects of stimulation upon corticospinal excitability perhaps because a homeostatic mechanism maintains the synaptic weights and firing within a physiological range, and so ensures that cortical excitability does not saturate (Siebner et al., 2004; Jung and Ziemann, 2009). So, the ability of continuous stimulation to prevent a decrease, rather than cause a decrease in corticospinal excitability, may be because the prior motor learning task altered the subsequent effects of stimulation. Alternatively, the decrease in corticospinal excitability due to continuous stimulation to the right hemisphere may prevent a decrease in corticospinal excitability in the left hemisphere due to reciprocal inhibition between the hemispheres (Di Lazzaro et al., 1999; Suppa et al., 2008).

Applying stimulation to either the DLPFC or M1 may simply be an experimentally convenient means to alter corticospinal excitability. Alternatively, DLPFC and M1 may be different parts of a circuit that controls the off-line processing of motor skill memories. The DLPFC is activated during motor sequence learning, is functionally connected to motor circuits, and so it becomes tempting to speculate that the DLPFC may have a role in biasing the excitability of motor circuits, including M1, to control those motor memories that will or will not be enhanced (Civardi et al., 2001; Willingham et al., 2002; Schendan et al., 2003). Thus, M1 and DLPFC may be components of a circuit that operates to physiologically control corticospinal excitability, and in turn determine those motor skill memories that will or will not be enhanced.
We have identified a physiological event that occurs after learning, which determines the fate of the newly acquired motor skill memory. A decrease in corticospinal excitability after learning a motor skill prevents off-line improvements, and so when this decline is prevented, by increasing corticospinal excitability, off-line improvements are induced. The decrease in corticospinal excitability after learning may be a physiological signal that prevents a newly acquired memory from being enhanced, or at least signals that its enhancement should be delayed until a more appropriate brain state such as sleep. The decrease of corticospinal excitability may prevent processes that are vital for the subsequent development of off-line improvements such as the neuronal replay of past events, or activity-dependent protein synthesis (Davis and Squire, 1984; Robertson, 2009; Carr et al., 2011). Equally, corticospinal excitability changes may act as a signal controlling the plasticity available within the motor cortex: recent work has shown that the retention of motor skill memories is related to the plasticity available within the motor cortex just after learning (Stefan et al., 2006; Cantarero et al., 2013a,b). Artificially replicating this signal may explain how applying $1 \mathrm{~Hz}$ TMS immediately after learning, which decreases corticospinal excitability, prevents off-line improvements over wakefulness, but these improvements still occurred over sleep (Chen et al., 1997; Robertson et al., 2005; Kantak et al., 2010). Conversely, preventing the signal by increasing corticospinal excitability, as we show here, can induce improvements. A similar signal may also control the stabilization of new or existing motor skill memories: applying $1 \mathrm{~Hz}$ stimulation over the motor cortex decreases cortical excitability and prevents memory stabilization during consolidation and reconsolidation (Muellbacher et al., 2002; Censor et al., 2010, 2014). Our observations suggest that motor skill improvements that arise from applying techniques that modify corticospinal excitability may do so because those techniques are modifying a signal that normally controls the fate of a motor skill memory (Reis et al., 2009; Galea et al., 2010).

Overall, neural processes conspire to determine the fate of a memory not only through the engagement of processes that support memory enhancement during consolidation, but also through a physiological signal that prevents motor skill enhancements, and so when that signal is abolished enhancement can occur. Having a combination of mechanisms that can either support or prevent memory processing may be essential for the refined control of a memory, which in turn may lead to its optimal long-term retention.

\section{References}

Aizenstein HJ, Stenger VA, Cochran J, Clark K, Johnson M, Nebes RD, Carter CS (2004) Regional brain activation during concurrent implicit and explicit sequence learning. Cereb Cortex 14:199-208. CrossRef Medline

Brown RM, Robertson EM (2007) Inducing motor skill improvements with a declarative task. Nat Neurosci 10:148-149. CrossRef Medline

Cantarero G, Tang B, O’Malley R, Salas R, Celnik P (2013a) Motor learning interference is proportional to occlusion of LTP-like plasticity. J Neurosci 33:4634-4641. CrossRef Medline

Cantarero G, Lloyd A, Celnik P (2013b) Reversal of long-term potentiationlike plasticity processes after motor learning disrupts skill retention. J Neurosci 33:12862-12869. CrossRef Medline

Carr MF, Jadhav SP, Frank LM (2011) Hippocampal replay in the awake state: a potential substrate for memory consolidation and retrieval. Nat Neurosci 14:147-153. CrossRef Medline

Censor N, Dimyan MA, Cohen LG (2010) Modification of existing human motor memories is enabled by primary cortical processing during memory reactivation. Curr Biol 20:1545-1549. CrossRef Medline

Censor N, Horovitz SG, Cohen LG (2014) Interference with existing memories alters offline intrinsic functional brain connectivity. Neuron 81:6976. CrossRef Medline 
Chen R, Classen J, Gerloff C, Celnik P, Wassermann EM, Hallett M, Cohen LG (1997) Depression of motor cortex excitability by low-frequency transcranial magnetic stimulation. Neurology 48:1398-1403. CrossRef Medline

Civardi C, Cantello R, Asselman P, Rothwell JC (2001) Transcranial magnetic stimulation can be used to test connections to primary motor areas from frontal and medial cortex in humans. Neuroimage 14:1444-1453. CrossRef Medline

Cohen DA, Pascual-Leone A, Press DZ, Robertson EM (2005) Off-line learning of motor skill memory: a double dissociation of goal and movement. Proc Natl Acad Sci U S A 102:18237-18241. CrossRef Medline

Davis HP, Squire LR (1984) Protein synthesis and memory: a review. Psychol Bull 96:518-559. CrossRef Medline

Di Lazzaro V, Oliviero A, Profice P, Insola A, Mazzone P, Tonali P, Rothwell JC (1999) Direct demonstration of interhemispheric inhibition of the human motor cortex produced by transcranial magnetic stimulation. Exp Brain Res 124:520-524. CrossRef Medline

Fadiga L, Buccino G, Craighero L, Fogassi L, Gallese V, Pavesi G (1999) Corticospinal excitability is specifically modulated by motor imagery: a magnetic stimulation study. Neuropsychologia 37:147-158. CrossRef Medline

Fischer S, Hallschmid M, Elsner AL, Born J (2002) Sleep forms memory for finger skills. Proc Natl Acad Sci U S A 99:11987-11991. CrossRef Medline

Galea JM, Albert NB, Ditye T, Miall RC (2010) Disruption of the dorsolateral prefrontal cortex facilitates the consolidation of procedural skills. J Cogn Neurosci 22:1158-1164. CrossRef Medline

Grafton ST, Hazeltine E, Ivry RB (1998) Abstract and effector-specific representations of motor sequences identified with PET. J Neurosci 18:9420 9428. Medline

Hardwick RM, Rottschy C, Miall RC, Eickhoff SB (2013) A quantitative meta-analysis and review of motor learning in the human brain. Neuroimage 67:283-297. CrossRef Medline

Hasan A, Galea JM, Casula EP, Falkai P, Bestmann S, Rothwell JC (2013) Muscle and timing-specific functional connectivity between the dorsolateral prefrontal cortex and the primary motor cortex. J Cogn Neurosci 25:558-570. CrossRef Medline

Hauptmann B, Reinhart E, Brandt SA, Karni A (2005) The predictive value of the leveling off of within session performance for procedural memory consolidation. Brain Res Cogn Brain Res 24:181-189. CrossRef Medline

Huang YZ, Edwards MJ, Rounis E, Bhatia KP, Rothwell JC (2005) Theta burst stimulation of the human motor cortex. Neuron 45:201-206. CrossRef Medline

Jung P, Ziemann U (2009) Homeostatic and nonhomeostatic modulation of learning in human motor cortex. J Neurosci 29:5597-5604. CrossRef Medline

Kantak SS, Sullivan KJ, Fisher BE, Knowlton BJ, Winstein CJ (2010) Neural substrates of motor memory consolidation depend on practice structure. Nat Neurosci 13:923-925. CrossRef Medline

Mars RB, Bestmann S, Rothwell JC, Haggard P (2007) Effects of motor preparation and spatial attention on corticospinal excitability in a delayed-response paradigm. Exp Brain Res 182:125-129. CrossRef Medline

Mills KR, Boniface SJ, Schubert M (1992) Magnetic brain stimulation with a double coil: the importance of coil orientation. Electroencephalogr Clin Neurophysiol 85:17-21. CrossRef Medline

Muellbacher W, Ziemann U, Wissel J, Dang N, Kofler M, Facchini S, Boroojerdi B, Poewe W, Hallett M (2002) Early consolidation in human primary motor cortex. Nature 415:640-644. CrossRef Medline

Nissen MJ, Bullemer P (1987) Attentional requirements of learning: evidence from performance measures. Cogn Psychol 19:1-32. CrossRef

Oldfield RC (1971) The assessment and analysis of handedness: the Edinburgh inventory. Neuropsychologia 9:97-113. CrossRef Medline

Pascual-Leone A, Wassermann EM, Grafman J, Hallett M (1996) The role of the dorsolateral prefrontal cortex in implicit procedural learning. Exp Brain Res 107:479-485. Medline

Paus T, Castro-Alamancos MA, Petrides M (2001) Cortico-cortical connectivity of the human mid-dorsolateral frontal cortex and its modulation by repetitive transcranial magnetic stimulation. Eur J Neurosci 14:14051411. CrossRef Medline
Petrides M, Alivisatos B, Meyer E, Evans AC (1993) Functional activation of the human frontal cortex during the performance of verbal working memory tasks. Proc Natl Acad Sci U S A 90:878-882. CrossRef Medline

Press DZ, Casement MD, Pascual-Leone A, Robertson EM (2005) The time course of off-line motor sequence learning. Brain Res Cogn Brain Res 25:375-378. CrossRef Medline

Reis J, Schambra HM, Cohen LG, Buch ER, Fritsch B, Zarahn E, Celnik PA, Krakauer JW (2009) Noninvasive cortical stimulation enhances motor skill acquisition over multiple days through an effect on consolidation. Proc Natl Acad Sci U S A 106:1590-1595. CrossRef Medline

Robertson EM (2007) The serial reaction time task: implicit motor skill learning? J Neurosci 27:10073-10075. CrossRef Medline

Robertson EM (2009) From creation to consolidation: a novel framework for memory processing. PLoS Biol 7:e19. CrossRef Medline

Robertson EM, Tormos JM, Maeda F, Pascual-Leone A (2001) The role of the dorsolateral prefrontal cortex during sequence learning is specific for spatial information. Cereb Cortex 11:628-635. CrossRef Medline

Robertson EM, Pascual-Leone A, Press DZ (2004a) Awareness modifies the skill-learning benefits of sleep. Curr Biol 14:208-212. CrossRef Medline

Robertson EM, Pascual-Leone A, Miall RC (2004b) Current concepts in procedural consolidation. Nat Rev Neurosci 5:576-582. CrossRef Medline

Robertson EM, Press DZ, Pascual-Leone A (2005) Off-line learning and the primary motor cortex. J Neurosci 25:6372-6378. CrossRef Medline

Sauseng P, Klimesch W, Gerloff C, Hummel FC (2009) Spontaneous locally restricted EEG alpha activity determines cortical excitability in the motor cortex. Neuropsychologia 47:284-288. CrossRef Medline

Schendan HE, Searl MM, Melrose RJ, Stern CE (2003) An FMRI study of the role of the medial temporal lobe in implicit and explicit sequence learning. Neuron 37:1013-1025. CrossRef Medline

Sibon I, Strafella AP, Gravel P, Ko JH, Booij L, Soucy JP, Leyton M, Diksic M, Benkelfat C (2007) Acute prefrontal cortex TMS in healthy volunteers: effects on brain 11C-alphaMtrp trapping. Neuroimage 34:1658-1664. CrossRef Medline

Siebner HR, Lang N, Rizzo V, Nitsche MA, Paulus W, Lemon RN, Rothwell JC (2004) Preconditioning of low-frequency repetitive transcranial magnetic stimulation with transcranial direct current stimulation: evidence for homeostatic plasticity in the human motor cortex. J Neurosci 24:3379-3385. CrossRef Medline

Spencer RM, Sunm M, Ivry RB (2006) Sleep-dependent consolidation of contextual learning. Curr Biol 16:1001-1005. CrossRef Medline

Stefan K, Wycislo M, Gentner R, Schramm A, Naumann M, Reiners K, Classen J (2006) Temporary occlusion of associative motor cortical plasticity by prior dynamic motor training. Cereb Cortex 16:376-385. CrossRef Medline

Strafella AP, Paus T, Barrett J, Dagher A (2001) Repetitive transcranial magnetic stimulation of the human prefrontal cortex induces dopamine release in the caudate nucleus. J Neurosci 21:RC157. Medline

Suppa A, Ortu E, Zafar N, Deriu F, Paulus W, Berardelli A, Rothwell JC (2008) Theta burst stimulation induces after-effects on contralateral primary motor cortex excitability in humans. J Physiol 586:4489-4500. CrossRef Medline

Walker MP, Stickgold R (2004) Sleep-dependent learning and memory consolidation. Neuron 44:121-133. CrossRef Medline

Walker MP, Brakefield T, Morgan A, Hobson JA, Stickgold R (2002) Practice with sleep makes perfect: sleep-dependent motor skill learning. Neuron 35:205-211. CrossRef Medline

Wassermann EM, Wang B, Zeffiro TA, Sadato N, Pascual-Leone A, Toro C, Hallett M (1996) Locating the motor cortex on the MRI with transcranial magnetic stimulation and PET. Neuroimage 3:1-9. CrossRef Medline

Willingham DB, Nissen MJ, Bullemer P (1989) On the development of procedural knowledge. J Exp Psychol Learn Mem Cogn 15:1047-1060. CrossRef Medline

Willingham DB, Salidis J, Gabrieli JD (2002) Direct comparison of neural systems mediating conscious and unconscious skill learning. J Neurophysiol 88:1451-1460. Medline

Yuan H, Perdoni C, Yang L, He B (2011) Differential electrophysiological coupling for positive and negative BOLD responses during unilateral hand movements. J Neurosci 31:9585-9593. CrossRef Medline 